\title{
PUXANDO A FUMAÇA E SOLTANDO PRO AR Consagração e silêncio em Pixinguinha e Dorival Caymmi
}

\section{Vítor Queiroz $(1)$}

E-mail: queiroz.vitor@gmail.com

\section{Rafael do Nascimento Cesar ${ }_{(2)}$ (D)}

E-mail: rafaelnascimentocesar1@gmail.com

(1) Universidade Federal do Rio Grande do Sul (UFRGS), Porto Alegre - RS, Brasil.

(2) Universidade Estadual de Campinas (Unicamp), Campinas - SP, Brasil.

DOI: $10.1590 / 3610606 / 2021$

\section{Introdução: mironga de preto velho}

Poucos nomes da música brasileira gozaram de tanto prestígio quanto Alfredo da Rocha Viana Filho (1897-1973), mais conhecido como Pixinguinha, e Dorival Caymmi (1914-2008). Seja entre a classe artística, seja perante o público em geral, o consenso acerca da importância de ambos solidificou-se ao longo das décadas e rendeu-lhes não apenas lugares cativos no cânone de nosso cancioneiro popular como também uma série interminável de homenagens e distinçôes. Feitas postumamente ou em vida, muitas dessas honrarias buscaram destacar tanto suas qualidades artísticas como morais. Sobre Pixinguinha, por exemplo, disse certa vez Vinicius de Moraes (1969, p. 8) tratar-se de um "santo humano", lisonja que o biógrafo Sérgio Cabral superou ao equiparar a morte do músico à

Artigo recebido em: 27/04/2020

Aprovado em: 22/09/2020 de Cristo (Cabral, 1980, p. 134). Com relação a Caymmi, o amigo Jorge Amado dedicou-lhe elogios em diversas ocasióes, comparando-o, por exemplo, a "uma flor de cultura, uma coisa esplêndida, única, luminosa” (Amado, 1985); mais tarde, Arnaldo Antunes, músico de outra geração, disse que sua obra "Não parece coisa feita por gente; parece o canto das coisas em si" (Antunes, 2000, p. 82).

Embora as carreiras desses artistas divirjam em relação ao momento histórico em que se consolidaram - Caymmi desponta na cena musical carioca quando Pixinguinha já era um veterano com problemas financeiros ${ }^{1}-\mathrm{e}$ aos gêneros musicais nos quais se fizeram conhecidos, ambos são paralelamente identificados como gênios dotados de qualidades inatas e associados a certas entidades místicas, como anjos, santos, espíritos iluminados ou até mesmo deuses e orixás. ${ }^{2}$ Qualificativos como esses, de tão frequentes, acabaram se convertendo em estereótipos estranhamente semelhantes. De um lado, "São 
Pixinguinha" arrebanhava fiéis ao tocar sua flauta ou seu saxofone. Do outro, "São Dorival”, o "protetor dos compositores", ainda zela pela criatividade e pelo ócio de seus devotos. ${ }^{3}$ Ainda que não tenham relação aparente, essas formas de renomeação indicam o cruzamento entre consagração e sacralidade em algum momento das trajetórias dos dois artistas.

Porém, se consideramos que as personas públicas, as imagens construídas a partir dos percursos biográficoprofissionais de tais "gênios", ancoram-se, em grande medida, na materialidade de seus corpos, geralmente projetando-os sobre os planos da natureza ou da sobrenatureza, logo surge um contraponto interessante em meio a essa consagração unânime. Com a possível exceção das fotografias nas quais aparecem, um relativo silêncio parece recair sobre uma parte visível e decisiva desses mesmos corpos: a cor da pele e outras marcas racializadas de ambos. ${ }^{4}$ Muito raramente esses elementos - associados sucessivamente, no Brasil dos séculos XIX e XX, a corpos "pretos", "de cor", "mulatos" ou "negros" - figuram no discurso de nossos protagonistas ou nos de seus admiradores e estudiosos. E se Pixinguinha afirmava "nunca [ter sofrido] o preconceito", mesmo sabendo que "o negro não era aceito com facilidade" no Rio de Janeiro de sua juventude (Pereira, 1997, p. 80), Caymmi, aquele que Jorge dizia ter a "cor do temporal" (Amado, [1947] 1967, p. 12), jamais lançou mão de uma identidade racial definida e isenta de ambiguidades.

Outro fato que chama a atenção é o envelhecimento social relativamente precoce de ambos. Aos 34 anos, em 1931, Pixinguinha já integrava, ao lado de Donga (Ernesto dos Santos), João da Baiana (João Guedes) e outros "veteranos", o conjunto musical Grupo da Guarda Velha. Já Dorival, "o homem de cabelos brancos e rosto moço” (Amado, [1947] 1967, p. 13), foi evocado por Antônio Carlos Jobim, em 1959, para chancelar simbolicamente a emergente bossa nova aos 45 anos de idade. ${ }^{6}$ À medida que se tornavam ícones de uma música pertencente a um tempo pregresso o primeiro com o choro carioca e o segundo com as cançôes praieiras de uma Bahia "tradicional [...] [de] vida urbana pré-industrial” (Risério, 1993, p. 63) -, Pixinguinha e Caymmi sofreram uma mudança de posição geracional dentro da MPB. Tal mudança produziu rebatimentos diretos na maneira como seus corpos foram ressignificados dentro dessa tradição. Nesse sentido, o passado de ambos, marcado pelos excessos da sociabilidade boêmia do Rio de Janeiro na primeira metade do século XX, ensejou-lhes um futuro pacato, no qual foram docilizados e domesticados ou, ainda, fixados em imagens atemporais de patriarcas bons e generosos.

Figuras análogas a essas são encontradas nas giras de umbanda do Sudeste brasileiro. Os pretos velhos, como são chamados, são entidades fortemente racializadas e envelhecidas, vindas diretamente dos tempos da escravidão com seus passos alquebrados (Slenes, 2007; Mattos e Abreu, 2016). Nas cantigas que acompanham a incorporação deles em seus fiéis, há também uma conexão entre bondade e qualidades inatas. Há uma delas, por exemplo, que diz: "Pai Benedito é bom / ele aprendeu sem ensinar" . Contudo, os pretos velhos são extremamente poderosos. Ao corporificar o passado - nesse caso, o "tempo do cativeiro" (cf. Mattos e Abreu, 2016) - em suas performances rituais, são capazes de presentificar a própria História para curar seus consulentes. ${ }^{8} \mathrm{E}$, sobretudo, sendo aparentemente inofensivos, os pretos velhos são mirongueiros, ou seja, escondem inúmeros feitiços e artimanhas:

Quem é aquele velhinho, que vem no caminho, andando devagar, com seu cachimbo na boca

puxando a fumaça e soltando pro ar?

Ele é do cativeiro,

é Pai Benedito, ele é mirongueiro. (Cf. a nota 7 acima.)

Embora este artigo não trate de Pai Benedito ou dos cultos afro-brasileiros (pelo menos não diretamente), gostaríamos de, em seu início, mostrar o paralelismo notável destas imagens, estereótipos ou narrativas personificadas. Perguntamo-nos, então, o que a cortina de fumaça de outros cachimbos - em nosso caso, da não enunciação de Pixinguinha e Dorival quanto a quaisquer questóes raciais - pode nos dizer a respeito da relação entre histórias presentificadas e pessoalizadas, o uso recorrente de metáforas (sobre) naturais para a descrição de determinadas figuras 
icônicas no interior de um campo artístico específico, a combinação indissociável de poder e fragilidade em processos de envelhecimento e, sobretudo, o lugar do silêncio na construção social de corpos racializados.

Para Larissa Nadai et al., a vinculação do silêncio ao "reino do incognoscível, da falta ou ausência de linguagem" (2019, p. 838) pode ser questionada se o elevarmos a um patamar heurístico focado no caráter produtivo contido no ato de silenciar. Em outras palavras, propomos pensar de que maneira o silêncio - tratado aqui como um viés analítico-metodológico (Queiroz, 2019b) - acerca de determinadas marcas sociais de Pixinguinha e Caymmi figurou como uma dimensão crucial de suas experiências raciais. Evitando repisar narrativas de invisibilização, nas quais sujeitos subalternizados são reduzidos a meros objetos sem agência, queremos sugerir que o silêncio sobre a negritude foi mobilizado, de modos peculiares, também pelos artistas, tornando-se constitutivo do próprio processo de consagração deles.

Vale dizer que esse fenômeno não atingiu apenas os músicos em questão, uma vez que corresponde a um efeito próprio de uma sociedade estruturalmente racista. Esse amplo processo de silenciamento, entretanto, pode ser melhor analisado em pessoas cujas trajetórias se notabilizaram na esfera pública. Como os pretos velhos da umbanda, nossos protagonistas foram transformados em entidades-mestras capazes de incorporar uma história coletiva sem, no entanto, renunciar a uma autonomia relativa. Resta-nos perguntar, afinal, se o silenciamento de suas marcas raciais náo faria parte da mironga de ambos.

\section{Silêncio na sala de visitas}

No livro Cor, profissão e mobilidade: o negro e o rádio de São Paulo, de João Baptista Borges Pereira, o nome Pixinguinha aparece somente ao final e uma única vez. De maneira discreta e sucinta, o autor o caracteriza como "outro elemento ligado à fase heroica da música popular carioca” (Pereira, 2001, p. 221) e transcreve trechos de uma entrevista realizada com o músico em abril de 1966. Ao estudar o processo de integração do negro ao meio radiofônico de São Paulo das décadas de 1920 a 1960, Borges Pereira viu na música popular um elemento-chave da sociedade brasileira a dar sentido "às mudanças que se operavam no plano da estrutura e no nivel da cultura" (2001, p. 28). Pixinguinha, tendo iniciado a carreira no Rio de Janeiro por volta de 1911, testemunhou a ascensão do rádio no Brasil e, ainda na década de 1920, quando esse meio de comunicaçáo estava em plena expansão, passou a integrar o quadro profissional da rádio Mayrink Veiga como arranjador e regente da Orquestra Victor Brasileira. Foi, portanto, um dos "primeiros pretos a entrar para o rádio tocando música popular" (Pereira, 2001, p. 222) e uma figura incontornável no entendimento da relação entre esse conjunto de transformaçóes (estruturais e culturais) e a população negra do país.

No entanto, o interesse de Borges Pereira em saber se Pixinguinha "teria sentido o problema de ser negro ao tentar frequentar ambientes grä-finos" quando jovem, em vez de inquiri-lo especificamente sobre música, como faziam seus admiradores e amigos, consistia em algo novo para o entrevistado. Tanto foi assim que o tom ambíguo e algo hesitante de sua resposta acabou provocando no entrevistador a dúvida "se $o$ tema do preconceito náo o preocupa ou se ele prefere evitá-lo" (Pereira, 1997, p. 80). Disse Pixinguinha:

Nunca senti o preconceito. Eram todos meus amigos e recebi muitos convites, mas o negro não era aceito com facilidade. Havia muita resistência. Eu nunca fui barrado por causa da cor porque nunca abusei. Sabia onde recebiam e onde não recebiam pretos. Onde recebiam eu ia, onde não recebiam, não ia. Nós sabíamos desses locais proibidos porque um contava para o outro. (apud Pereira, 1997, p. 80)

À primeira vista, a fala de Pixinguinha desdobra-se em duas. Por um lado, ela opera uma ação condicional, na qual os efeitos do racismo poderiam ser burlados segundo o manejo adequado de certas convençóes de sociabilidade e convívio. ${ }^{9}$ No caso do então jovem artista, cujo ofício o permitia transitar por entre espaços destinados a públicos de distintas extraçóes sociais, ele "sabia onde recebiam e onde não recebiam pretos" e, assim, era capaz de evitar o tipo de constrangimento próprio de quem "não era aceito com facilidade". Por outro lado, o trecho revela um comportamento ambíguo 
para com a norma tácita da desigualdade entre pretos e brancos. O reconhecimento da realidade regida por tal norma, com muitas prescrições e proscrições, não aparece no discurso de Pixinguinha, tornando difícil a apreensão de seu senso de pertencimento ou não a uma coletividade marginalizada. Ao não admitir ter sofrido o preconceito numa sociedade repleta dele, o músico apresenta um comportamento cindido e situado entre dois mundos sociais, os quais teria habitado de modo tanto precário como permanente.

Mas que mundos seriam esses? Como Pixinguinha teria aprendido a habitá-los? E, mais importante, por que a negação acerca do preconceito revelou-se uma saída possível a alguém com tanta notoriedade no meio da música popular? Por mais que as marcas raciais e sua eficácia na construção de hierarquias sociais sejam inegáveis, as maneiras como são vividas pelos sujeitos escapam à homogeneidade. Portanto, para tentar responder a essas questóes, é preciso reconstituir, ainda que brevemente, o espaço social por onde Pixinguinha se moveu, atuou e construiu relaçóes duradouras. Somente a partir daí podemos compreender, parafraseando o trabalho de Gustavo Rossi sobre o folclorista baiano Edison Carneiro, de que modo a raça agiu como um "operador simbólico" da experiência social de Pixinguinha, "bem como das percepçóes de si e de suas posiçóes na sociedade [carioca]" (2015, p. 90).

Nascido em uma família numerosa e remediada, Alfredo da Rocha Viana Filho não compartilhou da mesma origem social que a maioria dos músicos negros do Rio de Janeiro. Seu pai, Alfredo, era funcionário dos Telégrafos e mantinha uma casa espaçosa no bairro do Catumbi, onde abrigava a esposa, os nove filhos e hóspedes contumazes. Na "Pensão Viana", como foi carinhosamente apelidada, pessoas de classes sociais distintas reuniam-se para celebraçóes regadas a comida, bebida e música. ${ }^{10}$ Esta última, aliás, quase sempre ficava a cargo dos próprios residentes, músicos amadores que eram. Leonardo, Otávio e Henrique, irmãos mais velhos de Pixinguinha, tocavam violão e cavaquinho; o piano que havia na casa era de Edith, sua irmã; Dona Raimunda, mãe de Pixinguinha, cantava, e Seu Alfredo aventurava-se na flauta transversal. $\mathrm{Na}$ verdade, a inclinação dos Rocha Viana à música era tão presente que dois deles, Otávio (também conhecido como China) e Pixinguinha, aperfeiçoaramna rumo à profissionalizaçáo. $\mathrm{O}$ primeiro seguiu como autodidata; já o segundo contou com os ensinamentos de dois professores particulares, Irineu de Almeida e César Borges, e com uma flauta importada dada de presente por seu pai (Cabral, 1980, p. 13).

É por isso que, nas palavras do historiador Marc A. Hertzman, "a Pensáo Viana, a flauta cara de Pixinguinha e as aulas particulares de música indicam que sua família era parte de uma classe média distinta, senão totalmente afastada, das classes mais empobrecidas do Rio" (HERTZMAN, 2013, p. 118). ${ }^{11}$ De fato, a condição de classe dos Rocha Viana permitiu a Pixinguinha um acúmulo de trunfos sociais que, de saída, conferiram-lhe uma posição diferenciada no mercado musical. Além da educação regular, financiada pelo pai, a formação que Pixinguinha recebeu de seus tutores particulares fez que ele desenvolvesse intimidade com o instrumento bastante cedo e começasse a se apresentar profissionalmente aos 14 anos de idade em cabarés e teatros da cidade. Entretanto, por mais que os Rocha Viana estivessem mais próximos da classe média, jamais perderam os vínculos de solidariedade com outras famílias negras de estratos menos favorecidos. Provas disso eram os hóspedes costumeiros da Pensão Viana - músicos que, como Sinhô e Quincas Laranjeiras, contavam com muito prestígio e pouco dinheiro - e a amizade travada com Donga e Joáo da Baiana, moradores da Cidade Nova, àquela época um bairro considerado periférico e lar das chamadas "tias baianas" (cf. Moura, 1995; Carvalho, 2013).

A posição intermediária ocupada por Pixinguinha também foi decisiva em sua carreira profissional. Depois da estreia nos cabarés e casas de chope do bairro da Lapa, reduto da boemia local, o rapaz começou a acompanhar pequenas orquestras, como a do Teatro Rio Branco, e a entreter o público frequentador dos cinemas luxuosos do centro. Em outro raro momento da entrevista com João Baptista Borges Pereira, Pixinguinha comenta como esse tipo de atividade era organizado com base em pressupostos racistas:

Havia duas orquestras em cada cinema: uma ficava junto da tela, musicando a fita, que era muda. Outra ficava na sala de entrada, alegrando os 
frequentadores antes da fita começar. Artista preto só com muita paciência era aceito na orquestra de dentro. Assim, que nem ficar na cozinha, porque na sala de visita, na outra, de forma nenhuma (e ri da própria comparação). Me lembro que os únicos crioulos, que conseguiram tocar no Cine Palais antes das oito, foram um tal de Mesquita e o tio dele. (apud Pereira, 1997, p. 79)

Como era de se esperar, quando começou no Cine Palais, Pixinguinha trabalhava na sala de projeçóes "musicando a fita". Porém, em pouco tempo, o dono do estabelecimento, Isaac Frankel, ao perceber o sucesso que artistas como Ernesto Nazareth e Luciano Gallet faziam nas salas de esperas de outros cinemas, pediu a Pixinguinha que fizesse o mesmo no Cine Palais. O pedido foi prontamente aceito com a condição de que se formasse um conjunto "tudo de preto" nas palavras de Pixinguinha a Borges Pereira (1997, p. 79) - para entreter o público pagante. Desse conjunto nasceram Os Oito Batutas, talvez o grupo brasileiro mais famoso dos anos de 1920, dando-se início ao processo de consagração de Pixinguinha perante a crítica especializada da época. De Benjamin Constallat a Mário de Andrade, todos pareciam saudar as habilidades do jovem músico, ainda que sob perspectivas distintas e até mesmo conflitantes (Bessa, 2012, p. 98). "Quer dizer”, sintetizou astutamente o mestre do choro, "negro saía da cozinha e ia para a sala de visita" (apud Pereira, 1997, p. 79).

Com o êxito imediato dos Batutas no Cine Palais, personalidades da elite local começaram a prestar atenção àquela novidade - fosse pela cor dos músicos, fosse pela música que tocavam. Dentre elas, a figura que mais se destacou foi certamente Arnaldo Guinle, um dos filhos do magnata Eduardo Palassim Guinle. Desde logo, seu entusiasmo acerca dos Batutas o transformou no mais importante mecenas do grupo, financiando inclusive a viagem que fizeram a Paris (França) em outubro de $1921 .^{12}$ Lá, os rapazes (que já não eram mais oito e, sim, sete) se apresentaram ao lado das jazz bands estadunidenses no Shéhérazade e no Follies Bergère, lugares onde a exaltação do primitivismo musical revitalizava o interesse das vanguardas artísticas europeias pelos povos colonizados, além de ser "o contraponto da crise de identidade por que passava a França ao sair da Primeira Guerra" (Fléchet, 2017, p. 113). Por serem homens jovens e (em maioria) negros, os Batutas levavam aos olhos estrangeiros uma combinação altamente racializada de ritmos e corpos considerados "naturais" e "excessivos" a um só tempo (Radano, 2000). Ao regressar de Paris, em agosto de 1922, haviam ressituado o Brasil no imaginário racial europeu e se tornado símbolos incontestes do triunfo da música popular dentro e fora do país (Cabral, 1980).

No entanto, embora a admiração de Arnaldo Guinle pelos Batutas fosse sincera, não era capaz de suplantar certos limites simbólicos operados pelas gramáticas raciais em jogo na sociedade carioca. Pixinguinha conta que

O Guinle muitas vezes me convidava para a ir a um ou outro lugar. Eu sabia que o convite era por delicadeza e sabia que ele esperava que eu não aceitasse. $\mathrm{E}$ assim, por delicadeza, também não aceitava. Quando era convidado para tocar nesses lugares, tocava e saía. Não abusava do convite. (apud Pereira, 1997, p. 80)

Quando frequentava outras "salas de visita”, como a do próprio Guinle nos "saraus particulares" organizados por ele, Pixinguinha e seus companheiros nem sempre podiam contar com a certeza de serem pagos por seu trabalho. "Mas a gente nem pensava nisso", dissimulou Pixinguinha em seu depoimento ao Museu da Imagem e do Som (MIS), "A vida era tão boa... O que a gente queria era fazer música". Para a historiadora Virgínia de Almeida Bessa, essa falta de garantias era bastante representativa da "ainda incipiente profissionalização dos músicos populares" (2012 p. 113), o que faz sentido se nos lembrarmos do relato de Nestor de Holanda acerca de seus companheiros musicistas: "Quando cheguei ao Rio, todos os que conheci exerciam outras profissóes, ligadas ou não à música, para poder viver" (Holanda, 1969, p. 101). Porém, também subjaz a essa profissionalização precária o fato de as dinâmicas sociais ligadas à "prática geral do favor"(Schwarz, 2014, p. 48, grifo do autor), presentes desde o regime escravista, coexistirem contraditoriamente com os desejos modernizadores das classes dominantes - entre eles, a regulação das 
relaçóes de trabalho nos moldes capitalistas. Como "mediação quase universal" (p. 51, grifos do autor) das relaçóes sociais brasileiras, o favor amparava-se na manutenção silenciosa das distâncias que distinguiam os favorecidos de seus benfeitores, selando seus acordos com base em uma cumplicidade capaz de emular um vago senso de igualdade entre ambos. Nesse sentido, raça e classe operavam em conjunto como poderosos marcadores de diferença, organizando as fronteiras materiais e simbólicas de relacionamentos assimétricos, sem necessariamente serem enunciadas por ninguém.

Assim, ao não aceitar certos convites "por delicadeza" ou, quando por ventura os aceitava, não "abusava" deles, Pixinguinha evocava os códigos de uma etiqueta altamente racializada, na qual lhe era possível contornar (em parte) as desvantagens produzidas pela negritude somente se ele as dissimulasse. Tal dissimulação, para ocorrer efetivamente, precisava apelar ao regime de silenciamento que orientava as interaçóes entre pessoas de lugares sociais táo díspares quanto os de Pixinguinha e "o grande brasileiro Arnaldo Guinle", ${ }^{13}$ tornando possível a troca de favores entre eles. Caso o músico infringisse alguma dessas leis tácitas - ou, segundo ele próprio, "abusasse" das prerrogativas prescritas por sua posição dependente -, sua negritude acabaria sendo enunciada e sua mobilidade seria drasticamente reduzida. Segundo essa lógica contraditória, o jovem músico, na estreita margem de agência que possuía em relação a Guinle, tanto mais se favorecia quanto menos demarcasse a diferença e a desigualdade que, por sua vez, consistiam na base social do favor.

Trânsitos como esses continuaram por toda a vida de Pixinguinha. Até sua morte, aos 75 anos, ele acumulou prestígio o suficiente para figurar na consciência de especialistas como um marco definitivo de nossa música popular - em casos extremos, até como sinônimo dela. ${ }^{14}$ Tanto em suas qualidades pessoais como em seu talento considerado ímpar, Pixinguinha parecia encarnar os valores gestados pelos sentinelas de nossa tradição musical (cf. Fernandes, 2018): autêntico antes de ser famoso, brasileiro antes de ser negro. No entanto, na descrição de Borges Pereira, entrevemos uma faceta do artista jamais comentada por seus pares, sempre prontos a elogiar o "dono de uma bondade sem igual, amigo perfeito, modesto"
(Rangel, [1962] 2014, p. 67), tampouco ressaltada por ele mesmo.

Pixinguinha olha a seu redor, pensativamente. A impressão que me dá, naquele momento, é a de um homem triste, remoendo saudades [...] Há um silêncio prolongado entre nós, que chega a incomodar. A sensação que tenho é de que ele está distante, indiferente a tudo que o cerca, dialogando consigo mesmo, com suas memórias. (Pereira, 1997, p. 78)

A discrepância entre os relatos existentes sobre Pixinguinha e o descrito no trecho citado nos faz pensar se náo estamos diante de pessoas diferentes. Enfrentar o incômodo do antropólogo frente à opacidade do entrevistado é contrastá-lo com a imagem de um artista acessível e sem segredos a revelar. Imagem cuja eficácia de imortalizar-se no imaginário da música popular brasileira se deveu a uma condição de instabilidade estrutural acerca dos constrangimentos que pairavam sobre o músico. Enquanto pudesse se autoafirmar como alguém que não fazia distinções entre suas companhias - "Eram todos meus amigos" (apud Pereira, 1997, p. 80), lembra o mestre - porque sabia circular entre os mais diversos ambientes, Pixinguinha desviava a atenção alheia de suas marcas raciais, reorientando-a para outras marcas mais convenientes, digamos assim, ao projeto nacionalista do qual foi, a um só tempo, sujeito e objeto. Seu pertencimento a uma geraçáo "dourada" de sambistas e choróes foi uma dessas marcas (cf. Geraldo, 2007) e, nesse sentido, o "silêncio prolongado" entre ele e Borges Pereira nos reconduz àquilo que, ao menos no momento da entrevista, se tornara indissimulável.

\section{Um ourives do espaço vazio}

Em 1972, Dorival Caymmi lançou um dos discos mais importantes de sua longa vida artística. O LP, gravado pela Odeon e chamado simplesmente Caymmi, reúne um grande número de cançôes inéditas, indicando um pico de criatividade singular em sua trajetória (Caymmi, D., 1972). ${ }^{15}$ Além disso, 
tratava-se do seu trabalho mais "afro", nas palavras de seu filho e um de seus maiores intérpretes, Dori Caymmi. ${ }^{16}$

Permeado por músicas sobre orixás, sereias e uma famosa mãe de santo, o LP parece começar e terminar dentro de um terreiro. $\mathrm{O}$ toque do gan (uma campana metálica) e dos aguidavis (varetas) percutindo o couro dos três atabaques sagrados dos candomblés abre e fecha o disco. Sua última faixa, "Canto do Obá", traz, por fim, uma afirmação enfática, sobremarcada - nominal, em primeira pessoa e apresentando o cargo litúrgico ocupado pelo músico ${ }^{17}-\mathrm{da}$ adesão de Dorival a essa religião:

\section{Meu pai Xangô é meu pai Xangô}

Ê meu pai!

Protege teu filho, teu filho Caymmi

Dorival Obá Onikoyi

Esse LP e, particularmente, essa faixa correspondem às afirmaçóes mais próximas daquilo que podemos chamar de negritude em todo o percurso biográfico-profissional de nosso artista. Embora contenham informaçóes valiosas, nem os longos e bem-humorados depoimentos radiofônicos ou cinematográficos deixados por Caymmi revelam muita coisa a respeito de sua produção ou de suas posiçóes pessoais (Caymmi, [1972] 2009; Didier, 1999). Neles, Caymmi parecia mais interessado em contar boas histórias. Ao encarnar um personagem bonachão e tagarela, o "patriarca da música popular" (Amado, 1972) conseguia manter-se paradoxalmente calado frente aos microfones, sonegando a maioria de suas opiniôes e preservando sua intimidade. Sendo assim, Caymmi não costumava tematizar assuntos controversos como, por exemplo, qualquer tipo de preconceito. Da mesma forma, ele nunca fazia comentários diretos sobre sua identidade racial.

Poderíamos argumentar que Dorival não precisava necessariamente falar disso ou de qualquer outra coisa em suas entrevistas. Porém, se considerarmos que em suas obras tal relação entre conteúdos ditos e não ditos se inverte - nela não há nenhum personagem "branco(a)" e verifica-se uma insistente racialização elogiosa de inúmero(a)s "moreno(a)s", "preto(a)s", "nêgas" etc. -, esse silêncio torna-se, no mínimo, interessante. Tentamos, a seguir, respeitar a discrição do "bem-amado do povo e dos orixás" (Amado, [1947] 1967, p. 12), encarando-a como um "espaço vazio" (Caymmi, 2001, p. 376) que nos convida a avançar, além de seu discurso, em direção à sua própria experiência racial e à importância que essa temática assumia para ele. Para isso, faremos um breve détour pela velha Bahia dos tempos de seu pai e por um acontecimento que antecede imediatamente a gravação do LP de 1972.

De certo modo, Dorival refletia, com sua reserva cotidiana, a vivência de seu pai, Durval Caymmi (1878-1964), ou de seus companheiros de geração como, por exemplo, o já citado Édison Carneiro ou o rico empresário Miguel Sant'Anna (Azevedo, [1953] 1996; Rossi, 2015). Todos eles costumavam usar a burla da elegância e das boas maneiras, a aquisição de bens materiais, redes de proteçáo ou apadrinhamento social e, sobretudo, a discrição ou mesmo o embranquecimento identitário para contornar uma série de constrangimentos raciais e socioeconômicos.

Dorival, no entanto, provavelmente nunca se considerou - e, levando em conta a documentação disponível, raramente foi considerado - um homem branco. ${ }^{18}$ Ele era um dos muitos filhos de Seu Durval, mais conhecido como Ioiô, um sujeito humilde que teve a vida atravessada por constrangimentos associados à raça. Durval, fruto de uma união não reconhecida entre o filho de um imigrante e uma "mulata", nascera ainda no final do período escravista, na Salvador de Nina Rodrigues e de seu antagonista Manuel Querino (Corrêa, 2014; Albuquerque, 2002). Ele foi, até o fim de sua vida, um homem de côr extremamente elegante dividido entre as rodas semiclandestinas de samba ou de candomblé e o universo tido como respeitável do funcionalismo público na Bahia da virada do século XIX para o XX. As experiências e as negociaçōes raciais locais balizaram, evidentemente, sua trajetória simultaneamente individual e coletiva.

A influência, também silenciosa, do racismo à brasileira sempre esteve subliminarmente presente nos rumos trilhados por ele e por seu filho ilustre. Dorival Caymmi foi criado em um universo no qual as identidades e experiências raciais disponíveis eram radicalmente diferentes daquelas que vivenciamos no Brasil atual. $O$ país escapou por pouco do lado mais violento da segregação racial. Os jornais da 
juventude de Ioiô noticiavam regularmente, por exemplo, linchamentos de negros nas fazendas da província de São Paulo (Slenes, 2004, p. 15-26). A infância de Dorival, por outro lado, coincidiu com a recepção tensa - pelas associaçóes e frentes negras de então - da ascensão do horror segregacionista internacional na Europa, na África do Sul e nos Estados Unidos (Slenes, 2004). Não é à toa que a maioria das organizações de homens de côr da época - da imprensa negra nacional aos candomblés - decidiu apostar convictamente na retórica das máes pretas e da conciliação inter-racial por meio de um imaginário festivo que logo seria difundido por uma nascente indústria cultural de massa e pela intelectualidade nativa (Butler, [1998] 2000; Gomes, 2004; McCann, 2004).

Provavelmente, Caymmi não ignorava esses debates acirrados. Afinal, muitas das questões que estavam, então, na ordem do dia o afetavam duplamente enquanto artista popular e enquanto alguém socialmente visto como mulato ou mestiço - ou, no linguajar eufemístico do seu Certificado de Reservista, de 1936, como um sujeito de "Côrparda, Cabelo crespo [e] Nariz grande". ${ }^{19}$ É, também, difícil acreditar que tais questóes não tenham afetado a obra do "môço Caymmi" (Amado, [1947] 1967). Mas, nesse ponto, atingimos o limite das fontes e da discrição de nosso simpático compositor. Dorival, finalmente, testemunhou a derrubada do racismo científico de sua juventude. Ele não apenas viu essa mudança estrutural como também ajudou a promovê-la - junto a alguns de seus companheiros de geração, como seus grandes amigos Jorge Amado e Pierre Verger - direta ou indiretamente.

Suas obras, por outro lado, seguiram coerentemente um padrão de negociaçóes e soluçôes de compromisso entre elementos tidos como negro-baianos e uma linguagem musical peculiar, cheia de reminiscências eruditas e do jazz. Com o passar do tempo, suas músicas foram ficando cada vez mais espaçadas e sucintas, tendendo a um mínimo expressivo. Ou seja, a produção de Caymmi atingiu, nas últimas décadas de sua carreira, uma estética mais econômica e extremamente concentrada, uma vez que suas composiçôes - que também foram diminuindo em número - passaram a ser feitas com pouquíssimas palavras e gestos musicais elementares, expressandose, portanto, mais pelo silêncio, pelo vazio e pela sugestão que pelo acúmulo de informaçóes. ${ }^{20}$
Foi justamente entre 1967 e 1972 que essa virada expressiva ocorreu, junto a outras transformaçôes na carreira de Dorival. Nesse curto período, o músico, que vivia no Rio de Janeiro havia duas décadas, tinha voltado a Salvador por insistência de Jorge Amado, ganhando uma casa do governo local. Porém, nem tudo daria certo nesse retorno à terra natal. $\mathrm{Na}$ verdade, uma série de constrangimentos terminou por apressar a volta da família Caymmi ao Rio de Janeiro. Para exemplificá-los, mencionamos apenas um deles, precisamente ligado a questôes raciais.

Em 1970, o crítico de cinema Walter da Silveira sugeriu a candidatura de Caymmi para ocupar uma cadeira na Academia Baiana de Letras. A proposta agradou, aparentemente, a outros acadêmicos, a exemplo de Jorge Amado e do então presidente da casa, Wilson Lins. Ainda assim, algo esquisito parece ter acontecido no meio do caminho. Antes de analisálo, acessaremos a história em questão por meio de uma fonte de época. A edição de 21 de agosto de 1970, uma sexta-feira, do Jornal da Bahia, descreve vivamente a situação embaraçosa:

O presidente [...] da Academia Baiana de Letras, [o] escritor Wilson Lins, disse ontem que a Academia foi fundada por mulatos e negros, há meio século e tem sido até aqui uma instituição constituída por mestiços, entre os quais êle se inclui como "autêntico sarará".

Adiantou [...] que deve ter havido um equívoco da parte do informante, que transmitiu a sua amiga Stela Cay $[\mathrm{m}] \mathrm{mi}$ a notícia da existência, naquela Casa, de uma forte tendência racista, capaz de prejudicar a candidatura do grande poeta dos mares da Bahia. O informante, conforme já divulgado, foi o Professor Antônio de Assis Barros.

\section{Antes um mulato}

Prosseguindo, disse [...] que a própria cadeira, agora disputada, "vinha sendo ocupada por um eminente homem de côr, o saudoso escritor e historiador Afonso Ruy". 
"Muitíssimo equivocado, por conseguinte, andouse o informante da espôsa do imortal compositor da 'Preta do Acarajé', quando apresentou o suposto racismo existente na Academia como um obstáculo à candidatura do mais querido dos nossos poetas, sem dúvida alguma, aquêle que mais tem feito pela projeção da Bahia no Brasil e no mundo" - acrescentou.

\section{Caym[m]i náo perde}

O escritor Wilson Lins observou ainda que desistindo da candidatura que surgiu sob táo bons auspícios, Cay[m]mi nada perderá, [...] porque a decisão que êle hoje anuncia é episódica e passageira, podendo ser revista na primeira oportunidade, pois não conhece quem esteja em melhores condiçôes do que o imortal Cay $[\mathrm{m}] \mathrm{mi}$ para ocupar uma cadeira na Academia. "O meu voto êle teria tranquilamente. Com a sua desistência, não será por falta de mulato que qualquer outro acadêmico, inclusive eu, acabará votando em branco na próxima eleição" - concluiu, com humor. ("Wilson relembra...", Jornal da Bahia, 21/08/1970, p. 1$)^{21}$

Evidentemente, todo esse imbróglio diz mais sobre a sociedade baiana que lia e escrevia tais notícias nos anos 1970 que sobre os episódios antes relatados. Contudo, os eventos que teriam ocorrido naquela ocasiáo, e que os jornais de entáo nos deixam entrever, são extremamente interessantes. ${ }^{22}$

É impossível saber ao certo se a candidatura de Dorival foi ou não barrada pelo racismo de alguns dos membros daquela Academia ou por qualquer outro obstáculo institucional. Antônio de Barros, um livreiro pouco conhecido fora dos círculos literários locais, teria ido, no entanto, à nova casa dos Caymmi, em Salvador, para fazer uma intriga a respeito disso. Ele expôs, provavelmente em primeira mão, o convite feito ao "grande poeta dos mares da Bahia” e, simultaneamente, relatou à sua família que houvera uma reação racista contra a figura do compositor no interior da Academia.
Por mais infundado que seja um boato, é obvio que ele não pode surgir do nada. Ora, a eficácia de uma fofoca só pode ser verificada pela junção de posições sociais e de circuitos específicos - a Academia Baiana de Letras e um músico popular "de côr", por exemplo - com a dupla expectativa de que contextos tão diversos até podem relacionar-se, mas estão sujeitos a tensóes irredutíveis. De qualquer forma, a reação de Stella Caymmi, a esposa do compositor, surpreendeu Assis Barros. Ele não podia prever que, além de morder a isca, acreditando na possibilidade de haver mesmo uma conexão maldosa entre os dados e os agentes apresentados, a esposa de Dorival espalharia, indignada, tanto o boato em questão como a identidade do intriguista.

O impasse atravessaria, a seguir, a imprensa, as instituiçôes locais e a privacidade da família Caymmi. Assis Barros havia tocado numa questão delicada. A defesa da Academia feita por Wilson Lins revelava, consequentemente, um indisfarçável mal-estar. O presidente daquela agremiaçáo intelectual elitista que congregava e ainda congrega uma parcela bastante privilegiada da populaçáo letrada de Salvador - tentava identificar a si próprio e a instituição aos "mulatos e negros" que a teriam fundado. Porém, é sintomático que esses "eminente[s] home[ns] de côr" estivessem situados ora no passado "saudoso", ora no interior de um raciocínio comparativo que os ligava a um fenótipo, o "sarará". Essa categoria aproxima-se, com outras como "galego", precisamente da extremidade "branca" do confuso e contraditório espectro de identificaçôes raciais vigente, até hoje, em quase todo o Brasil.

Assis Barros tentou desmentir suas insinuaçóes indo outra vez à casa dos Caymmi (Queiroz, 2019a). Tendo em vista a personalidade resoluta de Stella e o histórico familiar do próprio músico, entretanto, a questão não pôde ser esquecida de modo tão simples. Defrontar-se com o racismo de uma instituição fosse ele real, virtual ou implícito - não deveria ser nada fácil para o filho de Ioiô e para sua mulher. O velho Durval havia se esmerado inutilmente em livrar-se dos constrangimentos raciais e de sua origem "abastardada" por meio da aparência e do consumo de determinados bens simbólicos. Uma cadeira na Academia representaria, provavelmente, a grande vitória da família de Ioiô contra o preconceito de 
côr. Stella tratou de encerrar definitivamente o caso, parando de receber os jornalistas interessados.

Contrariando as expectativas de Jorge Amado, que havia celebrado o "regresso definitivo de Dorival Caymmi ao mar da Bahia" na contracapa do LP de 1972 (Amado, 1972), seu grande amigo já se encontrava no Rio quando as cópias daquele disco foram prensadas pela Odeon, exatamente por conta desses e de outros dissabores. Seu lançamento arrematava uma série de mudanças na trajetória do músico. Além de reforçar as ligaçóes pessoais e profissionais que havia estabelecido, desde a década de 1940, com importantes criadores da cena artística baiana, como Verger ou Hector Bernabó, o Carybé, e de iniciar-se no candomblé, a partir daquela data Caymmi teve seu envelhecimento social ratificado. Desde então, por intermédio de inúmeros fiéis, regravadores, homenagens públicas etc., ele converteu-se, em sua longa velhice, numa verdadeira entidade, num santo ou numa instituiçâo consagradora, mesmo tendo se afastado progressivamente dos palcos, estúdios e espaços públicos durante essa fase da vida. Em meio a isso tudo Dorival havia, aparentemente, rompido seu silêncio habitual. Não teria ele afirmado, afinal, com um orgulho sobremarcado, sua negritude ao encerrar o LP em questão com seu "Canto do Obá"?

No entanto, se o escutarmos com atenção, perceberemos que, até nele, Dorival despistou qualquer assertiva direta utilizando habilmente certos dispositivos. Ainda que a canção seja executada pelo "cantor das graças da Bahia" no disco - colando aparentemente a voz do intérprete a seu enunciador-personagem e ambos ao compositor -, sua letra em primeira pessoa é, na verdade, de Jorge Amado (Caymmi, S., 2001, p. 253-254). Ora, desde a década de 1940, Jorge Amado, sempre que podia, mobilizava a figura de Caymmiàs vezes à revelia deste - para fins político-estéticos, enfatizando, junto a seus personagens ficcionais, seu caráter baiano, autodidata e autenticamente popular (Santos, A., 2015). Em segundo lugar, a letra da composição não fala em momento algum de cor ou de raça, a não ser indiretamente, por meio da referência ao candomblé. Fica a critério do ouvinte, conforme veremos, preencher o "espaço vazio". Por último, Dorival nem sequer compôs uma melodia nova para ela, reutilizando, sem alteraçóes, um trecho de "Cantiga de Cego" (Caymmi, D. T. et. al., 2013, faixa 10), composta para uma adaptação teatral do romance Terras do sem-fim, de Jorge Amado, publicado em 1943. A peça homônima foi encenada em 1947, aliás, pelo importantíssimo Teatro Experimental do Negro.

Por fim, se um dos primeiros sinais do envelhecimento social precoce de Caymmi foi, conforme indicamos na sexta nota deste artigo, o "P.S." escrito por Tom Jobim no LP inaugural da bossa nova, muitas décadas depois, o protagonista deste último disco, João Gilberto, mereceu um elogio entusiasmado de seu velho mestre. Embora Caymmi, mais uma vez, não tenha tematizado qualquer questão racial nesse depoimento concedido à sua neta, que então redigia a biografia dele, vale apena transcrevê-lo. Ao descrever essa outra figura icônica do panteão da MPB - um artista igualmente reservado, historicamente incontornável e possuidor de um vasto anedotário -, o compositor, agora nonagenário, finalmente parece cometer uma espécie de ato falho. Ainda que o comentário se refira especificamente à técnica musical de João Gilberto, Dorival nos deixa entrever que, de algum modo, ele também aquilatava, conscientemente, a equação proposta por este artigo ao articular a importância estratégica contida nos atos de silenciamento com a habilidade, o poder e o perigo. Às vezes, falamos de nós mesmos por meio de outras máscaras, de outras personas:

[...] ele deixa a zona vazia para botar o molho [...]. E João Gilberto é um ourives do espaço vazio, que obriga todo mundo a querer encher o tempo, essas bobagens. Ele não brinca com isso. $\mathrm{O}$ espaço vazio ele deixa para você. Para você construir, sentir, gozar. Ele deve ter achado a ourivesaria do negócio. Ele está atento, é perigosíssimo. (Caymmi, S., 2001, p. 376; 2008, p. 101)

\section{Conclusão: o Ogum bexiguento e um Xangô irresistível}

As trajetórias artísticas de Pixinguinha e Caymmi dizem respeito a dois momentos diferentes da história da música popular brasileira. O primeiro, marcando o início do século XX, costuma ser associado por especialistas a uma "Idade de Ouro" (Vasconcelos, 1984 , p. 21) supostamente ainda náo corrompida 
pela influência estrangeira ou por "qualquer interesse pecuniário" dos músicos (p. 21). Já o segundo, situado sobretudo a partir da década de 1930, corresponderia ao avanço da indústria cultural entre nós e à proliferação do rádio e dos discos. Também diferentes são os gêneros musicais associados a eles. Pixinguinha foi consagrado como um gênio do choro, embora tenha composto e tocado peças muito diversificadas; Caymmi notabilizou-se sobretudo pelo uso inovador da voz e do violáo e por seu minimalismo composicional. No entanto, ambos entraram no cânone de nossa música popular e lá permaneceram, escapando à imensa vala comum dos ilustres desconhecidos. Enfim, eles não se tornaram datados, mas dataram as geraçóes precedentes e seguintes.

Observar esse movimento bem-sucedido rumo à consagração coloca a pergunta fundamental sobre como o silêncio acerca da negritude de fato consagrou artistas negros(as) em certo momento da história cultural brasileira. Para tentar responder a ela, foi preciso, por um lado, rejeitar a separaçáo entre vida e obra, espécie de premissa balizadora em diversos estudos que postula a independência entre criadores e suas produçóes artísticas; por outro lado, notamos que as descriçōes e as imagens feitas de Pixinguinha e Caymmi por seus admiradores, biógrafos e amigos - bem como aquelas empreendidas por eles mesmos constituíam, do ponto de vista metodológico, o mesmo problema: como o silenciamento da negritude de ambos admitiu mais de um agente e, por consequência, mais de um significado. Em outras palavras, como se manifestou, enfim, em uma "expressão silenciosa" (Queiroz, 2019b, p. 760), múltipla e produtora de resultados imprevistos.

No caso de Pixinguinha, a não enunciação da negritude decorreu de sua dupla inserção na vida social carioca do início do século passado. Por um lado, como membro de uma família recém-saída da escravidão, mas cuja prosperidade relativa a posicionava dentro da lógica do favor; por outro lado, como músico popular negro vivenciando os dilemas do processo de modernização brasileira, em parte associado à valorização do samba como símbolo nacional, em parte associado à boemia e ao convívio com as classes mais estigmatizadas da cidade. Assim, os trunfos simbólicos cultivados por Pixinguinha em sua carreira musical puderam ser reconvertidos no capital social necessário a quem o benefício de um mecenas ou de um padrinho eram essenciais. Ao longo dos anos, tanto o virtuosismo que desempenhava como instrumentista quanto o lugar ocupado no panteão dos mestres do choro eram frequentemente equiparados, em termos de mérito pessoal, às relaçóes que manteve ao longo da vida e, acima de tudo, ao semblante bondoso e pacífico que lhe faziam conhecido. Diferentemente da entrevista concedida ao antropólogo Borges Pereira, a quem Pixinguinha julgava ser um "jornalista de São Paulo" (Pereira, 1997, p. 79) e cujo trabalho acadêmico desconhecia, no depoimento que deu, também em 1966, ao recém-criado Museu da Imagem e do Som do Rio de Janeiro (MIS-RJ), em nenhum momento o tema da raça aparece, seja como interpelação por parte dos entrevistadores, seja como desabafo por parte do depoente. ${ }^{23}$ E enquanto aspectos miúdos de sua vida eram escrutinados - e louvados - pela "nata da crítica, dos historiadores e dos pesquisadores" (Soares, 1969, p. 8) de nossa música, a questáo racial permanecia sob a forma de silêncio, na qual o "não narrável' se metamorfoseia na recusa deliberada em expressar-se" (Nadai et al., 2019, p. 844, grifos dos autores).

No caso de Dorival, o amplo círculo de amigos e aliados, a benevolência inabalável e a percepção fina do que era possível fazer em dado momento foram materializados de modo exemplar na gravaçáo do LP Caymmi (1972), na publicização cautelosa de sua relação com o candomblé e nas muitas entrevistas que deixou. Em todas as fontes disponíveis, da gravação inaugural de "O que é que a baiana tem?" até a cobertura jornalística de seu enterro, passando pelas incontáveis homenagens por ele recebidas, a cor do artista, suas experiências e os (prováveis) constrangimentos raciais pelos quais passou quase nunca são retratados. Nos documentos diretos (discos e entrevistas) a que temos acesso, Caymmi parecia, sobretudo, exercer de forma magistral um controle sobre seu tempo, desde seu silêncio e sua lentidáo proverbial - que geralmente faziam o público e as gravadoras esperarem anos ou mesmo décadas por um novo lançamento ou composição - até suas histórias e seus sorrisos sedutores que costumavam relativizar a relaçáo entre entrevistador e entrevistado nos documentários e programas de rádio nos quais 
aparece. Nas fontes indiretas (reportagens, regravaçóes, homenagens, conteúdo on-line etc.) chama a atenção o acúmulo de ambivalências em torno desse filho de Xangô envolvente e bonachão. Nelas, Dorival aparece alternadamente como um artista inovador e atemporal, inculto ou autodidata e sofisticado, baiano e carioca, mas, sobretudo - levando-se em conta, inclusive, as imagens nas quais sua pele escurece ou clareia a depender das técnicas fotográficas ou pictóricas utilizadas -, simultaneamente preto e branco.

As semelhanças entre Pixinguinha e Caymmi exploradas neste artigo buscaram oferecer uma leitura alternativa àquela que concebe as possibilidades de agência humana apenas como resposta direta a estruturas desiguais de poder ou como "sinônimo de resistência em relaçôes de dominaçâo" (Mahmood, 2006, p. 123). De fato, o ato de silenciar sobre os efeitos do racismo - ou mesmo de negá-los explicitamente como fazia Pixinguinha - pode parecer injustificável a qualquer artista negro(a) hoje. No entanto, se estendemos esse juízo às configuraçóes do passado, corremos o risco de nos ressentir quanto à conduta de certos sujeitos subalternizados ou de não compreender suas possibilidades de atuação mesmo em situaçóes de constrangimento evidentes. ${ }^{24}$

Apesar de não ser um enfrentamento direto às normas e às hierarquias raciais vigentes, o silêncio por parte dos artistas em questão lhes permitiu incorporar uma história coletiva - a história da chamada MPB -, ocupando o lugar de produtores de uma cultura legítima ou de marcos incontestes para uma historiografia feita por homens brancos e, finalmente, encarnando, infletindo e dando sentido a memórias simultaneamente públicas e privadas, repetidas sempre em homenagens, canonizaçóes, cronologias e outros gestos rituais (cf. Shaw, 2002; Palmié, 2002; Taussig, 1986). Em contrapartida, também fez deles a expressão viva de um acúmulo de ambivalências, em que a posição de sujeitos donos de uma arte altamente valorizada conviveu de maneira tensa com a de subalternos em relação aos círculos da classe dominante - lembremos os casos envolvendo Guinle e a Academia Baiana de Letras. ${ }^{25}$

Nesse sentido, o silêncio de Pixinguinha e Caymmi foi responsável pela demarcação de suas experiências raciais na medida em que buscou operar a desmarcação da negritude em ambos e, com isso, minimizar os estigmas individuais e familiares advindos do racismo. Nesse processo outras marcaçóes ganharam relevo. Nas imagens canônicas de ambos vê-se um estado de placidez, em que os símbolos associados ao envelhecimento (antes social que físico) de seus corpos, como a indumentária alinhada de Pixinguinha e os cabelos brancos de Dorival, parecem neutralizar os excessos cometidos por eles na juventude - o último era um sedutor notório; o primeiro, ainda de calças curtas, bebia, fumava e farreava. Da mesma forma, o tipo de masculinidade que performatizavam, caracterizada por uma virilidade supostamente perigosa porque negra, precisou ser sublimada em uma genialidade sem cor mil vezes exaltada.

No limite, se nos é impossível dimensionar o preço subjetivo pago por essas recusas e transfigurações, visto apenas de relance na figura "triste, remoendo saudades" do "filho de Ogum bexiguento"26 (Silva e Oliveira Filho, 1998) ou na tagarelice esquiva de Caymmi, talvez acertemos ao afirmar que tais expedientes não significaram uma sentença à objetificação, mas uma alternativa a ela. Uma alternativa sinuosa, às vezes difícil de apreender, engendrada nas próprias relaçôes que nossos músicos estabeleceram com seus entornos e, especialmente, concreta, mítica e leve, como os rolos de fumaça que, puxados por velhos espíritos afro-brasileiros, acabam se espalhando pelo ar dos terreiros quando estes são cruzados pelos corpos de seus fiéis.

\section{Agradecimentos}

Agradecemos à Fundação de Amparo à Pesquisa do Estado de São Paulo (Fapesp) pelo financiamento das pesquisas que possibilitaram a escrita deste artigo (processos n. 2012/22714-2 e 2016/02062-1). A Dorival Tostes Caymmi, mais conhecido como Dori, em nome de toda a família Caymmi, pelo apoio constante. Agradecemos, ainda, aos professores Christiano Key Tambascia, Gustavo Rossi e Heloisa Pontes, nossa querida orientadora, pela leitura generosa e pelos encontros regulares, mantidos mesmo sob as restriçóes impostas pela pandemia causada pela covid-19 em 2020. 


\section{Notas}

1 Pixinguinha viveu toda a sua vida no Rio de Janeiro (RJ), tendo iniciado a carreira profissional ainda nos primeiros anos da década de 1910. Além de flautista em grupos musicais de repertório variado, destacou-se como um dos principais arranjadores de música popular brasileira na primeira metade do século XX. Caymmi, por sua vez, nasceu em Salvador (BA), onde residiu até 1938, ano em que se mudou para a antiga capital federal acompanhado de seu violáo e iniciou sua carreira de compositor e intérprete.

2 Ver, por exemplo, Rangel ([1962] 2014, p. 67); Albin (1997, p. 41); Carvalho ([s.d.], p. 52); Caymmi (2001); Gil (1991, lado A, faixa 4).

3 São Pixinguinha dá título ao álbum de 1971, produzido por Hermínio Bello de Carvalho, que reúne sucessos da carreira de Pixinguinha. A expressão "São Dorival" aparece grafada em um santinho casualmente encontrado numa igreja de São Paulo (cf. Queiroz, 2019a, p. 222-223). Destacamos que tais referências, pouco conhecidas do grande público, são interessantes por sugerirem de forma explícita a relação entre a consagração e a sacralização dos artistas.

4 As noçóes de corpo, pessoa e persona utilizadas neste artigo são evidentemente devedoras das ideias de Marcel Mauss e devem ser entendidas, portanto, como fatos morais e/ou categorias do pensamento e não apenas (ou não necessariamente) como elementos biológicos. Cf. Mauss ([1950] 2003, p. 367-398).

5 A bibliografia sobre raça e relaçôes raciais no Brasil é particularmente extensa, tendo, ademais, desempenhado um papel fundamental na constituição do próprio campo intelectual brasileiro (especialmente nas Ciências Humanas) ao longo dos séculos XIX e XX. Indicamos, apenas a título de localização, a leitura dos dois últimos grandes balanços da produção nacional sobre o tema (Schwarcz, 1999; Pinho e Sansone, 2008) e outras publicaçôes recentes que vão da historiografia (Gomes e Domingues, 2014) e da investigação conceitual (Silva, 2007) a monografias etnográficas inovadoras (Dos Anjos, 2006). Também podem ser consultadas as referências contidas em nossos trabalhos anteriores (Cesar, 2018; Queiroz, 2011, 2019a).

6 A contracapa do primeiro álbum de Joáo Gilberto, assinada por Tom Jobim, apresenta o jovem intérprete e ressalta sua criatividade e sua "bossa". O texto termina com "P.S. - Caymmi também acha". Em outras palavras, Caymmi - artista da mesma gravadora, a Odeon - já naquela época dispensava apresentações. Seu primeiro nome era táo conhecido do público que não precisava ser mencionado e sua autoridade musical, tida como incontestável, bastava para atestar as qualidades do estreante, entâo desconhecido. Cf. Jobim (1959); Caymmi (2008).

7 Estes pontos de preto velho, bastante comuns nas giras de umbanda, também podem ser encontrados em livros dedicados aos adeptos dessa religião, como Modesto (2013, p. 192).

8 Cf. Shaw, 2002; Palmié, 2002, para uma discussão sobre memórias rituais. Em outra chave analítica, a respeito da incorporação da história em performances mágicoreligiosas, cf. ainda Taussig (1986).

9 A noçáo de burla, desenvolvida por Heloisa Pontes (2010) no contexto do teatro moderno paulista, aponta para a capacidade notável de certas atrizes de contornar constrangimentos inerentes a determinados marcadores sociais. No caso de Cacilda Becker, por exemplo, o domínio preciso das convençốes cênicas permitia-lhe fazer, no palco, um uso do corpo náo restrito a sua classe social, a seu gênero ou a sua idade. Retrabalhando a noção de burla no caso específico de Edison Carneiro, Gustavo Rossi (2015) argumenta que o acúmulo de distinçóes sociais de sua família permitiu-lhe contornar certos constrangimentos relativos à raça.

10 "Meu pai tocava choro na flauta e eu acompanhava. Não era um grande flautista, mas, naquela época, pra $\mathrm{mim}$, era o primeiro. Ele reunia na minha casa grandes figuras, como o Irineu de Almeida, Cândido Trombone, Viriato Ferreira, Neco, Quincas Laranjeira, aquela gente [...]. Lá em casa tinha festa todos os dias. Era uma casa com oito quartos: quatro em cima e quatro embaixo. Muita gente morou lá. Sinhô, por exemplo, morou lá. Era conhecida como Pensão Viana. De vez em quando encostava um caminhão e despejava 100, 200 garrafas de cerveja preta. Me lembro bem: cada garrafa custava 300 réis" (Museu da Imagem e do Som, 1966).

11 A citação foi traduzida pelos autores.

12 A ideia viera de Antônio Diniz, o "Duque", dançarino de maxixe que, na época, fazia sucesso em Paris (França) ao lado de Gaby, parceira a quem conheceu na mansão dos Guinle, em Botafogo, no Rio de Janeiro, segundo conta Jorge Eduardo Guinle (1997). Ao notar nos rapazes as qualidades que certamente cativariam o público da Cidade das Luzes - jovens negros tocando uma música "exótica" e dançável -, Duque convenceu Arnaldo Guinle a financiar a viagem para eles, a despeito das graves censuras feitas pela imprensa da época.

13 Assim se refere Donga a Arnaldo Guinle, em seu depoimento ao Museu da Imagem e do Som (MIS), em 1969 (Museu da Imagem e do Som, 1969).

14 O musicólogo e pesquisador Ary Vasconcelos certa vez escreveu: "Se você tem 15 volumes para falar de toda a música popular brasileira, fique certo de que é pouco. 
Mas, se dispóe apenas do espaço de uma palavra, nem tudo está perdido. Escreva depressa: Pixinguinha” (Vasconcelos, 1964, p. 84).

15 De suas treze cançôes, nove foram interpretadas pelo compositor pela primeira vez nesse LP: "Morena do mar" (faixa 2), "Santa Clara clareou" (faixa 3), "Canto de Nanâ” (faixa 4), "Dona Chica” (faixa 5), "Oração de Mãe Menininha" (faixa 6), "Eu cheguei lă" (faixa 7), "Vou ver Juliana" (faixa 11), "Itapoan" (faixa 12) e "Canto do Obá” (faixa 13). Todas foram feitas especialmente para esse disco e/ou eram composiçôes muito recentes. Excetuando-se seu LP inaugural, Cançôes praieiras, de 1954, é um caso único em sua carreira.

16 Em entrevista concedida a Vítor Queiroz em 3 de maio de 2012. A divulgação desse depoimento para fins acadêmicos foi concedida por Dorival Tostes Caymmi (Dori Caymmi).

17 Caymmi havia sido nomeado como um dos Obás de Xangô do famoso terreiro baiano do Opô Afonjá, ocupando, até morrer, esse cargo litúrgico prestigioso. Cf. Queiroz (2019b); Lima (2010).

18 Somados a sua discrição pessoal, os eufemismos correntes na primeira metade do século XX e que ainda são vigentes em determinadas situaçôes - como "moreno", "mestiço" ou mesmo "de côr"- tenderam a tirar ou minimizar as marcas raciais de Caymmi da maioria das referências disponíveis. É possível perceber, tangencialmente, essa percepção coletiva em seus documentos oficiais - nos quais seus traços físicos são explicitados - ou, significativamente, pelos olhos de seus admiradores estrangeiros. $\mathrm{O}$ escritor Albert Camus, por exemplo, assim o descreveu: "Kä̈mi, um negro que compóe todos os sambas que o país canta..." (Camus, [1978] 1997, p. 99).

19 O documento "Certificado de Reservista de $2^{a}$ Categoria", de 12 de fevereiro de 1936, está disponível no site do ADC (2009).

20 Para uma análise musical mais detida da obra de Caymmi, especialmente no que tange a sua escuta de Debussy, Massenet e outros compositores eruditos, ao lado de sua reapropriaçáo da linguagem dos jazz standards estadunidenses, conferir Queiroz (2015).

21 A reportagem "Wilson relembra que a Academia foi criada por negros e mulatos", publicada no Jornal da Bahia, em 21 de agosto de 1970, está disponível no site do ADC (2009).

22 Cf., a respeito, a série de reportagens sucessivas publicadas no Jornal da Babia: "Caymmi desiste da academia" (20 ago. 1970); "Wilson relembra que a Academia foi criada por negros e mulatos" (21 ago. 1970); "D. Stela: esta é a Academia de Caymi" (21 ago. 1970) e "Caymi" (22 ago. 1970). Todos esses textos estấo disponíveis no site do Acervo Dorival Caymmi (ADC, 2009).

23 Enquanto a entrevista com o antropólogo permaneceu inédita até 1997 - apenas fragmentos dela foram incorporados à versão final de Cor, profissäo e mobilidade, tese defendida em 1967 -, o depoimento de Pixinguinha ao MIS foi lançado poucos anos mais tarde, ao lado dos de Donga e João da Baiana. Chancelado pela Secretaria de Educação e Cultura do Rio de Janeiro, o livro As vozes desassombradas do museu (Museu da Imagem e do Som, 1970) foi a primeira publicação da série Depoimentos para a Posteridade, iniciativa capitaneada por Ricardo Cravo Albin, entấo diretor do MIS, que logo se tornou referência obrigatória a todos os interessados em escrever sobre música popular brasileira.

24 Luis Felipe Sobral faz uma advertência parecida em relação ao livro Antropólogas \& antropologia, de Mariza Corrêa (2003), ao afirmar que a hostilização do establishment masculino, embora seja comum e até mesmo inevitável, é também "um produto do julgamento cômodo que se pode realizar a respeito de um mundo social que o tempo consumiu", conduzindo à empatia ou ao ressentimento. "E o ressentimento", diz Sobral, "não leva senão, na melhor das hipóteses, a tentativas vâs de reabilitação de personagens históricas que, de um certo ponto de vista presente, perderam o jogo" (Sobral, 2018, p. 3).

25 Outro exemplo notável é o ator brasileiro conhecido como Grande Otelo. Luis Felipe Hirano conta que, trabalhando em uma companhia teatral no Rio de Janeiro nos anos de 1930, ele sonegava diante dos colegas a educação que recebera dos colégios tradicionais de São Paulo, "colocando-se no lugar esperado não apenas para recomeçar a carreira na arte teatral, mas também para o negro numa sociedade hierarquizada pela gradaçáo da cor" (Hirano, 2019, p. 109).

26 Ou seja, acometido na infância por uma doença que lhe deixara marcas e sendo filho - segundo a mitologia dos orixás (cf., por exemplo, Verger, 1981) - de um deus desbravador, mas que também é dado ao isolamento e/ou aos remorsos. A expressão, cunhada por Mário de Andrade em seu livro Macunaíma, dá título a uma das biografias do músico.

\section{REFERÊNCIAS}

ACERVO DORIVAL CAYMMI (ADC). 2009. Disponível em www.dorivalcaymmi.com.br, consultado em 20/12/2019. 
ALBIN, Ricardo Cravo. (1997), "Pixinguinha - 100 anos", in Museu da Imagem e do Som, Depoimentos para Posteridade, Rio de Janeiro, MIS.

ALBUQUERQUE. Wlamira. (2002), “Esperanças de boaventuras: construçôes da África e africanismos na Bahia (1887-1910)". Estudos Afro-Asiáticos, 24, 2: 215-246.

AMADO, Jorge. ([1947] 1967), "O môço Caymmi e a Bahia”, in D. Caymmi \& J. Amado, Cancioneiro da Bahia, São Paulo, Martins, p. 7-11

AMADO, Jorge. (1972), "Com tempo ainda curto...", in D. Caymmi, Caymmi, Rio de Janeiro, Odeon. 1 disco vinil, contracapa.

AMADO, Jorge. (1985), "Depoimento de Jorge Amado", in D. Caymmi. Caymmi: som, imagem e magia, Rio de Janeiro/Salvador, Odebrecht. 2 discos vinis, disco 1, lado $A$, faixa 1 .

ANTUNES, Arnaldo. (2000), 40 escritos. São Paulo, Iluminuras.

AZEVEDO, Thales de. ([1953] 1996), As elites de côr numa cidade brasileira. Salvador, EDUFBA.

BESSA, Virgínia de Almeida. (2012), A escuta singular de Pixinguinha: história e música popular no Brasil dos anos 1920 e 1930. São Paulo, Alameda.

BUTLER, Kim. ([1998] 2000), Freedoms given, freedoms won: Afro-Brazilians in post-abolition, São Paulo and Salvador. New Brunswick, Rutgers University Press.

CABRAL, Sérgio. (1980), Pixinguinha: vida e obra, Rio de Janeiro, Lidador.

CAMUS, Albert. ([1978] 1997), Diário de uma viagem. Rio de Janeiro, Record.

CARVALHO, Bruno. (2013), Porous city: a cultural history of Rio de Janeiro. Liverpool, Liverpool University Press.

CARVALHO, Hermínio Bello de. ([s.d.]), "São Pixinguinha". Disponível em http://www. dominiopublico.gov.br/download/texto/mre000118. pdf, consultado em 3/4/2020.

CAYMMI, Dorival. (1972), Caymmi. Rio de Janeiro, Odeon. 1 disco vinil.

CAYMMI, Dorival. ([1972] 2009), Dorival Caymmi: Programa Ensaio. Sáo Paulo, TV Cultura. 1 DVD.
CAYMMI, Dorival T. (Dori), CAYMMI, DinahirT. (Nana) \& CAYMMI, Danilo. (2013), Nana, Dori e Danilo: Caymmi. São Paulo, Som Livre. 1 CD.

CAYMMI, Stella. (2001), Dorival Caymmi. São Paulo, Editora 34.

CAYMMI, Stella. (2008), Caymmi e a bossa nova. Rio de Janeiro, Ibis Libris.

CESAR, Rafael do Nascimento. (2018), "A fragata negra: tradução e vingança em Nina Simone". Mana - Estudos em Antropologia Social, 24, 1: 39-70.

CORRÊA, Mariza. (2003). Antropólogas \& antropologia. Belo Horizonte, Editora UFMG.

CORRÊA, Mariza. (2014), As ilusóes da liberdade: a escola Nina Rodrigues e a antropologia no Brasil. Rio de Janeiro, Fiocruz.

DIDIER, Aluísio (dir.). (1999), Um certo Dorival Caymmi. Rio de Janeiro, Rio Filmes. 1 DVD.

DOS ANJOS, José Carlos Gomes. (2006), No território da linha cruzada: a cosmopolitica afro-brasileira. Porto Alegre, UFRGS.

FERNANDES, Dmitri Cerboncini. (2018), Sentinelas da tradiçâo: a constituiçâa da autenticidade no samba e choro. São Paulo, Edusp.

FLÉCHET, Anaïs. (2017), Madureira chorou... em Paris: a música popular brasileira na França do século XX. São Paulo, Edusp.

GERALDO, José. (2007), "História e historiadores da música popular no Brasil". Latin American Music Review, 28, 2: 271-299.

GIL, Gilberto. (1991), Parabolicamará. Rio de Janeiro, WEA. 1 disco vinil.

GOMES, Flávio \& DOMINGUES, Petrônio (org.). (2014), Politicas da raça: experiências e legados da abolição e da pós-emancipação no Brasil. São Paulo, Selo Negro.

GOMES, Tiago de Melo. (2004), Um espelho no palco: identidades sociais e massificação da cultura no teatro de revista dos anos 1920. Campinas, Editora Unicamp.

GUINLE, Jorge Eduardo. (1997), Um século de boa vida. Rio de Janeiro, Editora Globo.

HERTZMAN, Marc A. (2013), Making samba: a new history of race and music in Brazil. Durham, Duke University Press. 
HIRANO, Luis Felipe Kojima. (2019), Grande Otelo: um intérprete do cinema e do racismo no Brasil (1917-1933). Belo Horizonte, Editora UFMG.

HOLANDA, Nestor de. (1969), Memórias do Café Nice: subterrâneos da música popular e da vida boêmia do Rio de Janeiro. Rio de Janeiro, Conquista.

JOBIM, Antonio Carlos. (1959), "João Gilberto", in J. Oliveira (João Gilberto), Chega de Saudade, Rio de Janeiro, Odeon. 1 disco vinil.

LIMA, Vivaldo da Costa. (2010), Lesse Orixá: nos pés do santo. Salvador, Corrupio.

MAHMOOD, Saba. (2006), "Teoria feminista, agência e sujeito liberatório: algumas reflexôes sobre o revivalismo islâmico no Egipto”. Etnográfica, 10, 1: 121-158.

MATTOS, Hebe \& ABREU, Martha. (2016), “A história como performance: jongos, quilombos e a memória do tráfico ilegal de escravizados africanos", in A. Mauad et al. (org.), História Pública no Brasil, São Paulo, Letra e Voz, p. 221-235.

MAUSS, Marcel. ([1950] 2003), Sociologia e antropologia. São Paulo, CosacNaify.

McCANN, Bryan. (2004), Hello, Hello Brazil: popular music in the making of modern Brazil. Durham, Duke University Press.

MODESTO, Luís (Babá Luis de Xogum). (2013), O livro da nação espírita. Itaquaquecetuba, Ed. do Autor.

MORAES, Vinicius de. (1969), "Mulher, bebida, a vida e a morte segundo Vinicius". O Pasquim, 6: 8.

MOURA, Roberto. (1995), Tia Ciata e a pequena África no Rio de Janeiro. Rio de Janeiro, Prefeitura da Cidade do Rio de Janeiro/Secretaria Municipal de Cultura.

MUSEU DA IMAGEM E DO SOM. (1966), Depoimento de Alfredo da Rocha Viana Filho ("Pixinguinha"). Rio de Janeiro, MIS.

MUSEU DA IMAGEM E DO SOM. (1969), Depoimento de Ernesto Maria dos Santos ("Donga"). Rio de Janeiro, MIS.

MUSEU DA IMAGEM E DO SOM. (1970), As vozes desassombradas do museu. Rio de Janeiro, Secretaria de Educação e Cultura.
NADAI, Larissa, CESAR, Rafael do Nascimento \& VEIGA, Cilmara. (2019), "De venenos, escutas e assombraçóes: caminhos para etnografar o silêncio". Mana-Estudos em Antropologia Social, 25, 3: 837-850.

PALMIÉ, Stephan. (2002), Wizards and scientists: explorations in Afro-Cuban modernity and tradition. Durham, Duke University Press.

PEREIRA, João Baptista Borges. (2001), Cor, profissão e mobilidade: o negro e o rádio de São Paulo. São Paulo, Edusp.

PEREIRA, João Baptista Borges. (1997), "Pixinguinha". Revista do Instituto de Estudos Brasileiros, 42: 77-87.

PINHO, Osmundo Araújo \& SANSONE, Lívio (org.). (2008), Raça: novas perspectivas antropológicas. Salvador, ABA/EDUFBA.

PONTES, Heloisa. (2010), Intérpretes da metrópole. São Paulo, Edusp.

QUEIROZ, Vítor. (2011). Olha só, ô meu Tambú, como chora o candongueiro: as estrelas e os toques $d a$ tradiçấo no jongo de Guaratinguetá e Campinas-SP. Dissertação de mestrado, Instituto de Filosofia e Ciências Humanas, Universidade Estadual de Campinas, Campinas.

QUEIROZ, Vítor. (2015), "Cançóes praieiras", in M. Santana \& C. Leal (org.). Cem anos de Dorival Caymmi. Salvador, EDUFBA, p. 71-88.

QUEIROZ, Vítor. (2019a), Dorival Caymmi: a pedra que ronca no meio do mar. Rio de Janeiro, Papéis Selvagens.

QUEIROZ, Vítor. (2019b), “O corpo do patriarca: uma etnografia do silêncio, da morte e da ausência”. Mana-Estudos de Antropologia Social, 25, 3: 743-776.

RADANO, Ronald. (2000), "Hot fantasies: American modernism and the idea of black rhythm", in R. Radano \& P. Bohlman (org.). Music and the racial imagination. Chicago, University of Chicago Press, p. 459-479.

RANGEL, Lúcio. ([1962] 2014), Sambistas e choróes. Rio de Janeiro, Instituto Moreira Salles.

RISÉRIO, Antônio. (1993), Caymmi: uma utopia de lugar. São Paulo/Salvador, Perspectiva/COPENE. 
ROSSI, Gustavo. (2015), O intelectual feiticeiro: Édison Carneiro e o campo de estudos das relaçôes raciais no Brasil. Campinas, Editora Unicamp.

SANTOS, André Domingues dos (2015). "Bahia a dois: consonâncias e dissonâncias na parceria entre Dorival Caymmi e Jorge Amado", in M. Santana \& C. Leal (org.), Cem anos de Dorival Caymmi, Salvador, EDUFBA, p. 35-54.

SCHWARCZ, Lilia. (1999), "Questão racial e etnicidade", in S. Miceli (org.), O que ler na Ciência Social brasileira. São Paulo, Sumaré, p. 267-325.

SCHWARZ, Roberto. (2014). As ideias fora do lugar: ensaios selecionados. São Paulo, Companhia das Letras.

SILVA, Denise Ferreira da. (2007), Toward a global idea of race. Minneapolis, University of Minnesota Press.

SHAW, Rosalind. (2002), Memories of the slave trade: ritual and the historical imagination in Sierra Leone. Chicago, University of Chicago Press.

SILVA, Marília T. Barboza da \& OLIVEIRA FILHO, Arthur L. de. (1998), Pixinguinha: filho de Ogum bexiguento. Rio de Janeiro, Gryphus.

SLENES, Robert. (2007), “Eu venho de muito longe, eu venho cavando': jongueiros cumba na senzala centro-africana", in S. Lara \& G. Pacheco (org.), Memórias do jongo: as gravaçôes históricas de Stanley J. Stein - Vassouras, 1949. Campinas, CECULT, p. 110-124.

SLENES, Robert. (2004), “'O horror, o horror!': o contexto da formação de identidades mestiças no Rio de Janeiro dos anos 1920", in T. de M. Gomes, Um espelho no palco. Campinas, Editora Unicamp, p. 15-26.

SOARES, Shirley. (1969), "Museu da Imagem e do Som: uma ação cultural dinâmica". Jornal de Letras, 228: 8, junho.

SOBRAL, Luis Felipe (2018), "Lady Frazer e seu marido. Gênero e anomalia na história da antropologia”. Cadernos Pagu, 54: e185406.

TAUSSIG, Michael (1986), Shamanism, colonialism and the wild man: a study in terror and healing. Chicago, University of Chicago Press.

VASCONCELOS, Ary. (1964), Panorama da música popular brasileira. São Paulo, Martins.

VASCONCELOS, Ary. (1984), Carinhoso etc.: história e inventário do choro. Rio de Janeiro, Editora do Livro.

VERGER, Pierre. ([1951] 1981), Orixás. Salvador, Corrupio. 


\section{PUXANDO A FUMAÇA \\ E SOLTANDO PRO AR: CONSAGRAÇÁO E SILÊNCIO EM PIXINGUINHA E DORIVAL CAYMMI}

\author{
Vítor Queiroz, Rafael do Nascimento \\ Cesar
}

Palavras-chave: Pixinguinha, Dorival Caymmi, silêncio, raça e envelhecimento.

Este artigo trata das correlações entre raça, envelhecimento e silêncio presentes nas trajetórias de dois artistas negros da música popular brasileira: Alfredo da Rocha Viana Filho, ou Pixinguinha, e Dorival Caymmi. Recuperando alguns momentos decisivos de seus processos de consagração perante a crítica especializada e a historiografia da música popular, o artigo procura evidenciar como o silêncio acerca de determinadas marcas sociais de ambos, notadamente a cor, figurou como uma dimensão crucial de suas experiências raciais. Nas biografias e entrevistas existentes, salvo raríssimas exceçóes, Pixinguinha e Caymmi não são identificados como negros, ao passo que abundam referências à idade e à genialidade deles. Além disso, a não enunciação $\mathrm{da}$ negritude, analisada no contexto específico de suas trajetórias como instrumentistas e compositores, pode ser entendida também como estratégia, empregada por eles próprios, para tentar burlar certos constrangimentos decorrentes do racismo presente na sociedade brasileira.

\section{INHALING AND RELEASING SMOKE: CONSECRATION AND SILENCE IN PIXINGUINHA AND DORIVAL CAYMMI}

\author{
Vítor Queiroz, Rafael do Nascimento \\ Cesar
}

Keywords: Pixinguinha, Dorival Caymmi, silence, race and aging.

This article deals with the correlations between race, aging and silence present in the trajectories of two black Brazilian popular music artists, Alfredo da Rocha Viana Filho, or Pixinguinha, and Dorival Caymmi. Recovering some decisive moments of their consecration processes in the face of specialized criticism and the historiography of popular music, this study seeks to demonstate how the silence concerning certain social marks of both artists, notably color, figured as a crucial dimension of their racial experiences. In existing biographies and interviews, with very few exceptions, Pixinguinha and Caymmi are not identified as black, while references to their age and genius abound. In addition, the non-enunciation of blackness, analyzed in the specific context of their trajectories as instrumentalists and composers, can also be understood as a strategy employed by themselves in an attempt to circumvent certain constraints resulting from the racism present in Brazilian society.

\section{FUMER ET RECRACHER LA FUMÉE: CONSECRATION ET SILENCE CHEZ PIXINGUINHA ET DORIVAL CAYMMI}

\author{
Vítor Queiroz, Rafael do Nascimento \\ Cesar
}

Mots-clés: Pixinguinha, Dorival Caymmi, silence, race et vieillissement.

Cet article analyse les corrélations entre race, vieillissement et silence présentes dans les trajectoires de deux artistes noirs de la musique populaire brésilienne: Alfredo da Rocha Viana, surnommé Pixinguinha, et Dorival Caymmi. À partir de moments décisifs de leurs processus de consécration vis-à-vis de la critique spécialisée et de l'historiographie de la musique populaire, le travail souligne combien le silence autour de certaines marques sociales des deux artistes, et notamment leur couleur de peau, s'est imposé comme une dimension essentielle de leurs expériences raciales. À de rares exceptions près, Pixinguinha et Caymmi ne sont pas identifiés comme des Noirs dans les biographies et les interviews existantes. En revanche, les références à leur âge et à leur génialité sont nombreuses. En outre, la non-énonciation de la négritude - analysée dans le contexte spécifique de leurs parcours en tant qu'instrumentistes et compositeurs - peut aussi être entendue comme une stratégie utilisée pour échapper à des contraintes en lien avec le racisme présent dans la société brésilienne. 